The acquisition of the English future tense by Iranian EFL learners: Processing instruction vs. meaningful output-based instruction

Vafaparvar, Samaneh $\bowtie$

Sobhe Sadegh Institute of Higher Education, Iran (samavafaparvar@yahoo.com)

Shiela, Kheirzadeh

Sobhe Sadegh Institute of Higher Education, Iran (sh.kheirzadeh@yahoo.com)

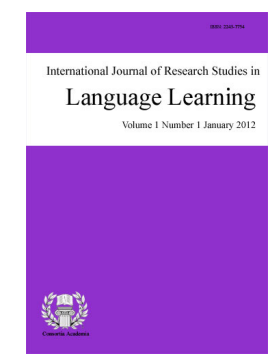

ISSN: 2243-7754 Online ISSN: 2243-7762

OPEN ACCESS

Received: 26 May 2017

Revised: 15 June 2017

Accepted: 23 June 2017

Available Online: 25 June 2017 DOI: $10.5861 /$ ijrsll.2017.1847

\title{
Abstract
}

This study was designed to investigate the impact of processing instruction and meaningful output-based instruction on the acquisition of English future tense. For this purpose, 33 Iranian female learners were randomly selected and assigned to one of the three groups of processing instruction (PI) $(n=10)$, meaningful output-based instruction (MOBI) $(n=10)$, and control group $(n=13)$. A distinct instructional treatment was conducted for the experimental groups. Besides, a pretest/posttest procedure was administered to assess the effect of instruction. The findings indicated that PI group had significant gains on interpretation tasks compared to MOBI group and control group. For production tasks, MOBI group outperformed PI and control group. It should be noted that for both interpretation and production tasks, both experimental groups improved significantly and outperformed the control group. The statistical analysis conducted on the delayed posttest revealed that PI outperformed MOBI group in both interpretation and production tasks. The results suggest that although MOBI can lead to acquisition, PI exerts a positive effect which sustains over time and might positively influence learners' interlanguage development.

Keywords: processing instruction; meaningful output-based instruction; English future tense; EFL learners 


\section{The acquisition of the English future tense by Iranian EFL learners: Processing instruction vs. meaningful output-based instruction}

\section{Introduction}

Recently, researchers have shown an increased interest in the field of grammar teaching and also many teaching approaches have been suggested in this regard. Among these approaches, it is widely agreed today that explicit grammar instruction plays a vital role in learning a new language since it has a strong impact on the development of EFL learners' grammar knowledge. In other words, explicit grammar instruction provides a suitable ground by which L2 learners can learn the structures of a new language more effectively.

Oe of the most controversial approaches for teaching grammar is processing instruction (PI). PI is a kind of form-focused instruction which deals with processing information via comprehension practice by L2 learners (VanPatten, 1996). Another major approach that has dominated the field of grammar instruction is output-based instruction (OBI). In this approach, learners concern with the production of input rather than the interpretation of form. According to Swain (1995, 2000, 2005), output is a crucial way, just like input, in developing L2 system. Output-based instruction provides learners with a suitable ground by which learners are pushed from semantic processing, that is required for comprehending input, to the syntactic processing, which is needed to encode meaning (Swain, 1995).

The issues of processing instruction and output-based instruction have received considerable critical attention. To begin with, some studies have shown the impact of PI on the learning of various features of Spanish language system (see VanPatten, 1996). These studies have suggested that processing instruction is the most beneficial approach for learning grammar. According to these studies, PI helps L2 learners reinforce their ability to process input and also it facilitates access to the target feature while performing different kinds of production tasks such as written and oral tasks. All in all, PI focuses on the explicit role of grammar teaching and strategies used by L2 learners (VanPatten, 1996).

According to VanPatten (2004a), output-based instruction (OBI) may play some important roles in language development but it cannot lead to the acquisition of the target form of language. Output- based instruction uses the traditional Audio-lingual method in which lots of mechanical drills are used. These traditional instructions of OBI have been criticized by VanPatten. He believes that the interpretation of form is superior to its production. He also proposed that the developing system should at first create the relevant intake data in order to produce it (VanPatten, 1995).

On the other hand, Erlam (2003) suggested that output-based instruction is superior to input-based instruction. Erlam reviewed some studies in the area of PI and OBI and concluded that in most studies, both PI and OBI group have the same performance on interpretation and production tasks. However, in some cases, learners receiving output-based instruction improve more than processing instruction group. Therefore, the much debated question is whether input-based instruction leads to successful grammar acquisition or an output-based instruction. The present study aims at finding the answer to this question considering an EFL context.

\section{Literature Review}

\subsection{Input processing}

The concept of input and information theory turned to the central focus in SLA research and theory. One of the most important theories that is derived from input and information processing theory is VanPatten's input processing model (see VanPatten, 1996, 2002, 2004). VanPatten (1990b) was one of the first researchers who 
applied the principles of information theory in the area of input processing (Cadierno, 1993) and proposed communicative processing strategy which refers to the preference of L2 learners to process input for meaning in the first stage and then they focus on the form of input. The input processing theory deals with "the initial process by which learners connect grammatical forms with their meaning as well as how they interpret the roles of nouns in relationship to verbs" (VanPatten, 2004, p. 5). Differently stated, input processing model focuses on how L2 learners process input in order to make form-meaning connections.

VanPatten $(1996,2002)$ proposed a new model that is grounded on input processing model which is called processing instruction (PI). Processing instruction "is a type of explicit grammar instruction that is informed by a model of how L2 learners initially process L2 input to make form-meaning connections, that is to say, VanPatten's model of input processing (1996, 2002)" (VanPatten, 2004, p. 33). The PI model operates under three internal mechanisms or sets of process (VanPatten, 1996). Morgan-Short and Bowden (2006) state that these mechanisms include input processing, accommodation and restructuring processes, and those processes which are involved in language production like monitoring and control (Figure 1).

(1)

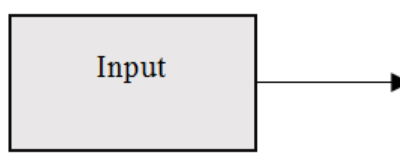

(Working Memory)

1. Input Processing

2. Accommodation and Restructuring

3. Access
(2)

(3)

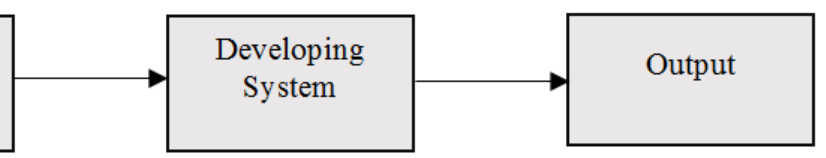

Figure 1. Basic Processes in Acquisition (VanPatten, 2004, p. 33)

\subsection{Output hypothesis}

The evidence from the past studies introduced another approach called the output hypothesis. Some researchers (e.g., Izumi, 2002; Swain, 1995; Swain \& Lapkin, 1995) worked on determining the role of output on second language acquisition. These SLA researchers questioned Krashen's (1989) view about the effectiveness of input in the development of linguistic system. They believed that output is also an important factor in developing the linguistic system; therefore, they proposed the output hypothesis which deals with mental processes that are an important part of the L2 process (Swain, 1995, 1998; Swain \& Lapkin, 1995).

In studies by Farley (2001a, 2001b), the participants were divided into two groups of instruction: processing instruction (PI) and meaningful output instruction (MOI). In this study, both processing instruction and meaningful output instruction included non-paradigmatic grammatical explanation, some information on processing strategy and input through examples. In the meaningful output instruction, no mechanical activity is used. MOI instrument included some meaning-based activities in which learners should use both meaning and form at some level during production (VanPatten, 2004). Additionally, in MOI group, students should involve in some communicating tasks and produce output. The only difference was that the participants in MOI group were presented by output-based practice in utterance-initial position instead of structured input activity. Feedback was also provided in these studies; however, no control group was used. It should be noted that all activities were developed based on the original guidelines of VanPatten and Cadierno (1993). The result of the first study, Farley (2001a), indicates that on the interpretation tasks, PI performs better than the MOI group. However, like previous PI studies, no differences were observed between PI and MOI on the production tasks. Surprisingly, the result of Farley (2001b) suggested no difference in the performance of participants on both interpretation and production tasks. 
In the study by Benati (2005), three groups of TI, PI, and MOI were compared with each other considering the linguistic development of the English simple past tense. In TI group, explicit explanation of grammatical point and output practice (both mechanical and meaning-oriented activities) were presented to Chinese and Greek school-age learners of English. In contrast, in PI and MOI groups, the instructor presented the explicit information about the grammatical feature, information about the strategies, and structured input activities. Feedback was also provided for all groups. According to Benati (2005) "three sets of materials developed for this experiment were balanced in terms of activity types, use of visuals and vocabulary which consisted in highly frequent items" (p. 76). It is noteworthy to state that in the processing instruction packet, participants have been provided with some information about the processing problem while the traditional instruction packet just dealt with the explanation of rules (Benati, 2005). The result indicated that PI group outperformed TI and MOI groups on interpretation task. However, all three groups performed similarly on the production task. Benati concluded that output plays a vital role in language learning; however, it cannot lead to language acquisition in an implicit system.

Another study in the area of meaningfulness was carried out by Morgan-Short and Bowden (2006) where the first-semester Spanish participants were divided into three groups of instruction, namely processing instruction, meaningful output-based instruction and control group. The target form in this study was Spanish preverbal direct object pronouns delivered by computer. Participants of both experimental groups have been presented with meaningful input- or output- based practice. The results indicated that MOBI and PI groups performed equally similar on immediate and delayed posttests for both interpretation and production tasks. On the production tasks, MOBI group performed better than PI while no difference was observed in the performance of the two groups in the delayed posttest. Morgan-Short and Bowden suggest that "MOBI can, like PI, lead to linguistic development, at least when practice is meaningful and leads learners to make form-meaning connections" (p. 59).

Based on the aforementioned issues, the present study seeks to find the difference among processing instruction group, meaningful output-based instruction group, and control group in learning English future tense; therefore, the following research questions were posed for the present study.

$>$ Q1. Is there any difference among processing instruction group, meaningful output-based instruction group, and control group with respect to their performance on the interpretation task of English future tense?

$>$ Q2. Is there any difference among processing instruction group, meaningful output-based instruction group, and control group with respect to their performance on the production task of English future tense?

$>$ Q3. Is there any difference between processing instruction and meaningful output-based instruction groups in the delayed posttests of interpretation and production?

\section{Method}

\subsection{Participants}

In this study, forty Iranian EFL learners at pre-intermediate level from Pajoohesh Language Institute in Isfahan, Iran, were randomly selected. All participants were female and they ranged in age from 14 to 52 . They had all covered the American English File, Starter book, and their level of English language proficiency was approximately the same. In order to make the students more homogeneous, the proficiency level of participants was checked by giving a test about future tense. Participants who were familiar with the target form were excluded from the study. The final subject pool consisted of thirty three participants who were divided into three groups of processing instruction $(n=10)$; meaningful output-based instruction $(n=10)$; control group $(n=13)$. 


\subsection{Instrument}

Two instructional materials, consisted of two different instructional packets, were utilized in this study. The first instructional packet was developed for the processing instruction group and the second instructional packet was developed for meaningful output-based instruction. It should be noted that the instructional packets for both groups were identical and the only difference was in the nature of the activities. In other words, the activities in PI group were interpretation-based tasks while MOBI group activities were based on the production of the target form. The same explanation of grammatical rules was presented for both groups and the nature and amount of feedback for both PI and MOBI group were alike. Besides the instructional packages, one pretest and two posttests were administered.

\subsection{Procedure}

Thirty three homogenized participants were selected for the present study who were taught by the same teacher at the same institute. According to similar studies in this area, a pretest can provide a vital baseline measure in order to observe the initial knowledge and ability of the participants. In this case, a pretest is a suitable means of eliminating participants with initial knowledge of English future tense. In order to meet this end, a pretest which consisted of both production and interpretation tasks was presented to the participants one week before the onset of the treatment. Afterwards, the participants were assigned to two groups of instruction, namely processing instruction group, meaningful output-based instruction group and a control group. It needs to be mentioned that the researcher was the teacher of all the three groups.

The present study aimed to investigate the differences between two types of explicit grammar instruction. In order to meet this end, two sets of materials were developed. The first set of materials was processing instruction packet that was used in the processing instruction group which included the presentation of explicit explanation of English future form, some examples and ten structured input activities. These activities consisted of ten referential and affective input activities (aural and written) which were covered in the classroom. In these activities, the participants were required to interpret the sentences and the target form without any production.

The second set of materials selected for the present study was meaningful output-based instructional packet that was used in MOBI group. This packet consisted of explicit explanation of the grammatical point, with some examples. The same as PI group, ten output-based activities (oral and written) were covered in the classroom. In this case, the participants just dealt with the production of the grammatical point not the interpretation process. The PI and MOBI activities used in both packets were inspired by instructional packets used by Farley (2001) and Benati (2005). All versions of activities had equal number of visuals and vocabulary items. It should be noted that the participants in control group dealt with a number of reading passages and comprehension questions and no feedback of any kind was provided.

As it was mentioned before, the instructional packet for both PI and MOBI groups had identical vocabulary and explicit grammar explanation. Moreover, both PI and MOBI had the same amount of feedback and time to complete the activities. In the case of wrong responses by participants, the instructor requested another participant to give the right answer until the correct response was provided. On the first day of the treatment, participants were provided with the explicit explanation of target form and some examples. On the second day of treatment, five activities including two referential activities, two affective activities, and one activity with both referential and affective features were presented in both experimental groups. On the other hand, five other activities were administered on the third day of treatment.

\section{Results}

In order to answer the first research question and also to find the effect of instruction type on the way in which learners interpret the target form, a one-way between groups ANOVA was run. Tables 1 and 2 shows the descriptive statistics and the result of one way between groups ANOVA for the interpretation scores, 
Vafaparvar, S., \& Shiela, K.

respectively.

\section{Table 1}

Descriptive Statistics for Interpretation Task

\begin{tabular}{|c|c|c|c|c|c|c|c|c|}
\hline & \multirow[b]{2}{*}{$N$} & \multirow[b]{2}{*}{ Mean } & \multirow[b]{2}{*}{$S D$} & \multirow[b]{2}{*}{$S E$} & \multicolumn{2}{|c|}{$\begin{array}{l}\text { 95\% Confidence Interval for } \\
\text { Mean }\end{array}$} & \multirow[b]{2}{*}{ Minimum } & \multirow[b]{2}{*}{ Maximum } \\
\hline & & & & & Lower Bound & Upper Bound & & \\
\hline PI & 10 & 16.00 & .94 & .29 & 15.32 & 16.67 & 15.00 & 17.00 \\
\hline MOBI & 10 & 12.60 & 1.07 & .33 & 11.83 & 13.36 & 11.00 & 14.00 \\
\hline Control & 13 & 9.53 & 1.33 & .36 & 8.73 & 10.34 & 7.00 & 12.00 \\
\hline Total & 33 & 12.42 & 2.93 & .51 & 11.38 & 13.46 & 7.00 & 17.00 \\
\hline
\end{tabular}

Table 2

Multiple Comparisons for Interpretation Task

\begin{tabular}{llccccc}
\hline & & & & & \multicolumn{2}{c}{$95 \%$ Confidence Interval } \\
\cline { 5 - 7 } (I) Group & (J) Group & Mean Difference (I-J) & SE & Sig. & Lower Bound & Upper Bound \\
\hline PI & MOBI & $3.40^{*}$ & .51 & .00 & 2.13 & 4.66 \\
& Control & $6.46^{*}$ & .48 & .00 & 5.26 & 7.65 \\
\multirow{2}{*}{ MOBI } & PI & $-3.40^{*}$ & .51 & .00 & -4.66 & -2.13 \\
& Control & $3.06^{*}$ & .48 & .00 & 1.86 & 4.25 \\
\hline
\end{tabular}

Note. $* *$. The mean difference is significant at the 0.05 level.

As it can be seen, there was a statistically significant difference at the $p<.05$ level in interpretation scores for the three groups: $\mathrm{F}(2,30)=89.4, p=.00$. Besides reaching statistical significance, the actual difference in mean scores between the groups was quite large. The effect size, calculated using eta squared, was .85. Post-hoc comparisons using the Tukey HSD test indicated that the mean score for PI Group $(\mathrm{M}=16.00, \mathrm{SD}=.94)$ was significantly different from MOBI Group $(\mathrm{M}=12.60, \mathrm{SD}=1.07)$ and control Group $(\mathrm{M}=9.53, \mathrm{SD}=1.33)$.

In order to answer the second research question and also to determine the effect of instruction type on the way in which learners produce the target form, a one-way between group ANOVA was run, the results of which are presented in Tables 3 and 4.

Table 3

Descriptive Statistics for Production Task

\begin{tabular}{lcccccccc}
\hline & & & \multicolumn{7}{c}{$95 \%$ Confidence Interval for } \\
\cline { 6 - 7 } & & & & & \multicolumn{2}{c}{ Mean } & & \\
\cline { 6 - 7 } & $N$ & Mean & $S D$ & $S E$ & Lower Bound & Upper Bound & Minimum & Maximum \\
\hline PI & 10 & 13.20 & 1.03 & .32 & 12.46 & 13.93 & 12.00 & 15.00 \\
MOBI & 10 & 16.00 & 1.24 & .39 & 15.10 & 16.89 & 14.00 & 18.00 \\
Control & 13 & 9.30 & .63 & .17 & 8.92 & 9.68 & 8.00 & 10.00 \\
Total & 33 & 12.51 & 3.00 & .52 & 11.45 & 13.57 & 8.00 & 18.00 \\
\hline
\end{tabular}

Table 4

Multiple Comparisons for Production Task

\begin{tabular}{llccccc}
\hline & & & & & \multicolumn{2}{c}{$95 \%$ Confidence Interval } \\
\cline { 5 - 7 } (I) Group & (J) Group & Mean Difference (I-J) & SE & Sig. & Lower Bound & Upper Bound \\
\hline PI & MOBI & $-2.80^{*}$ & .43 & .00 & -3.87 & -1.72 \\
& Control & $3.89^{*}$ & .40 & .00 & 2.88 & 4.90 \\
\multirow{2}{*}{ MOBI } & PI & $2.80^{*}$ & .43 & .00 & 1.72 & 3.87 \\
& Control & $6.69^{*}$ & .40 & .00 & 5.68 & 7.70 \\
\hline
\end{tabular}

Note. ${ }^{* *}$. The mean difference is significant at the 0.05 level.

As it can be seen in Tables 3 and 4, there was a statistically significant difference at the $p<.05$ level in production scores for the three groups: $\mathrm{F}(2,30)=137.4, p=.00$. Besides reaching statistical significance, the 
The acquisition of the English future tense by Iranian EFL learners

actual difference in mean scores between the groups was quite large. The effect size, calculated using eta squared, was .90. Post-hoc comparisons using the Tukey HSD test indicated that the mean score for MOBI Group (M $=16.00, \mathrm{SD}=1.24)$ was significantly different from PI Group $(\mathrm{M}=13.2, \mathrm{SD}=1.03)$ and control Group $(\mathrm{M}=9.30$, $\mathrm{SD}=.63)$

Finally, in order to answer the third research question, two independent samples T-Test were conducted for both experimental groups (PI and MOBI). First of all, an independent sample T-Test was conducted to compare interpretation scores at delayed posttest (two weeks after the instruction). The means and standard deviations are presented in Table 5. The analysis of the interpretation scores suggests a significant difference in scores for PI group $(\mathrm{M}=15.40, \mathrm{SD}=.96)$ and MOBI group $(\mathrm{M}=11.30, \mathrm{SD}=.94 ; \mathrm{t}(18)=9.57, p=.00$, two-tailed $)$. The magnitude of the differences in the means (mean difference $=4.1,95 \%$ CI: 3.20 to 4.99 ) was very large (eta squared $=.83)$.

Table 5

Group Statistics for Interpretation Scores

\begin{tabular}{lllllc}
\hline & Group & $N$ & Mean & $S D$ & Std. Error Mean \\
\hline Interpretation Task & PI & 10 & 15.40 & .96 & .30 \\
& MOBI & 10 & 11.30 & .94 & .30 \\
\hline
\end{tabular}

Another independent samples T-Test was conducted to compare production scores at delayed posttest in order to explore the third research question (two weeks after the instruction). The means and standard deviations are presented in Tables 6 . The analysis of the production scores indicates a significant difference for PI group (M $=13.00, \mathrm{SD}=.81)$ and $\mathrm{MOBI}$ group $(\mathrm{M}=14.30, \mathrm{SD}=1.25 ; \mathrm{t}(18)=-2.75, p=.013$, two-tailed $)$ in production scores. The magnitude of the differences in the means (mean difference $=-1.3,95 \% \mathrm{CI}:-2.29$ to -.30 ) was large (eta squared $=.29)$.

\section{Table 7}

Group Statistics for Production Scores

\begin{tabular}{llllcc}
\hline & Group & $N$ & Mean & SD & Std. Error Mean \\
\hline Production Task & PI & 10 & 13.00 & .81 & .25 \\
& MOBI & 10 & 14.30 & 1.25 & .39 \\
\hline
\end{tabular}

The comparison of PI and MOBI mean scores showed that the PI group gained more permanent results than MOBI in the delayed posttest. For one thing, PI had a higher mean score $(\mathrm{M}=15.4)$ comparing to MOBI $(\mathrm{M}=11.3)$ on the interpretation task. Moreover, the PI group had a better mean score on the production task $(\mathrm{M}=13.00)$ than MOBI group $(\mathrm{M}=14.30)$. All in all, it can be stated that in both interpretation and production tasks, PI outperformed MOBI and had more permanency in acquiring the English future tense.

\section{Discussion and Conclusion}

The first research question of the present study concerned the difference between processing instruction group, output-based instruction group, and control group with respect to their performance on the interpretation of English future tense. Referring to the findings of previous researchers (Morgan-Short \& Bowden, 2006; Farley 2001b; Nagata, 1998; Toth, 2006), it was believed that PI and MOBI groups would have a similar performance on the interpretation tasks. Though the results of the interpretation tasks, in the present study, indicated that the participants in the two experimental groups (PI and MOI) outperformed the participants in the control group, the PI group performed best $(\mathrm{PI}>\mathrm{MOBI} \geqslant \mathrm{Control})$.

It seems that the results of this study on the interpretation tasks were consistent with several studies that have proven the superiority of PI over MOBI (e.g., Benati, 2005; Benati, 2001a; Farley, 2001). The present finding supports the idea that the processing instruction group may have significance gains in grammar. It is noteworthy to state that MOBI group also made significant gains; however, their performance on the 
interpretation tasks was not as significant as PI group. It can be concluded that PI has improved the participants' interpretation strategies which may help them better interpret the English future tense. In other words, PI helps learners create form-meaning connections for the process of acquisition and it has positive effects on learners' developing systems. As Benati (2005) states, " the fact that the PI group performed better than the MOI group in the interpretation task clearly indicated that structured input activities are the causative factor in the improved performance of learners as both groups received the same amount and type of explicit information" (p. 85). However, the finding of this question is inconsistent with that of some other researchers (e.g., Morgan-Short and Bowden, 2006; Farley 2001b; Nagata, 1998; Toth, 2006) who reported similar performance of both PI and MOBI groups on the interpretation tasks

As noted before, some studies have suggested that PI has a vital role in the acquisition of second languages. For instance, in some previous studies, the effectiveness of PI was examined in the acquisition of grammatical structures such as Italian future and simple past, French causative, object pronouns in English, Japanese honorifics, Spanish subjunctive, Spanish copulas ser and estar and Spanish past tense. The findings of the present study are particularly important in that the PI group had a better performance and significant gains on interpretation tasks in the case of learning English future tense by Iranian EFL learners. To put it differently, this study shows that PI positively influences the acquisition of English future tense; therefore, it suggests an empirical evidence for the use of PI to teach this tense to Iranian EFL learners.

Moreover, the findings of the first research question can be discussed in the light of input processing model of SLA. This model suggests that input-based instruction in which input plays the major role in the process of teaching have a better effect on L2 learners' developing system (Cadierno, 1993). According to Cadierno (1993), "input-oriented processing instruction seems to have provided learners with knowledge available for both comprehension and production while output-oriented traditional instruction seems to have provided knowledge available only for production" (p.166). A further possible explanation for this finding is related to the nature of acquisition in L2 learner's knowledge system. As Cadierno (1993) points out "processing instruction operates on the processes by which input is converted into intake, thus feeding correct data into the learner's developing system" (p. 167). In this case, it can be stated that MOBI operates on the processes which account for how learners make output, thus resulting in a knowledge system different from the one created by PI.

And finally, the finding of this question confirms VanPatten's input processing model of acquisition (VanPatten, 1990, 1996, 2002, 2004a) and has gone some way towards enhancing our understanding of learner's input processing and the way of deriving intake from input. All in all, it seems important to reiterate that the results of PI in this study have proven the findings of previous PI studies stated that PI significantly influences both interpretation and productions tasks and this teaching approach would demonstrate an efficient grammar instruction by which L2 learners might be able to gain accuracy and fluency in grammar.

The second research question of this study concerned the difference between processing instruction group, output-based instruction group, and control group with respect to their performance on the production of English future tense. The finding of the production tasks indicated that the participants in the two experimental groups (PI and MOBI) outperformed the participants in control group; however, MOBI group performed better than PI group in production tasks $(\mathrm{MOBI} \geqslant \mathrm{PI}>\mathrm{Control})$.

The finding of the production tasks were consistent with several studies that have proven the superiority of MOBI over PI (e.g., Morgan-Short \& Bowden, 2006; Dekeyser \& Sokalski, 1996; Allen, 2000; Nagata, 1998; Cheng, 2002; Collentine, 1998; Farley, 2001b; Izumi \& Bigelow, 2000). One possible explanation for this result is that the participants in MOBI group may have been able to conduct or reinforce form-meaning connections in both output-based and input-based practice (Fukuda, 2009). According to Dekeyser (1997, cited in Fukuda, 2009), productive tasks and the receptive tasks can facilitate the process of acquisition of productive knowledge and learners' performance on the receptive knowledge. However, it cannot be concluded that "the element of output practice in and of itself affected the developing system" (Morgan-Short \& Bowden, 2006, p. 56). 
According to Morgan-Short and Bowden, it can be concluded that an output-based instruction contains some input directed to linguistic development.

The results of the present study on the production tasks are parallel to the findings of Farley and Aslan (2012). Both studies have concluded that MOBI performed better on the production tasks after the treatment. According to Farley and Aslan (2012), this result may be due to some factors. First of all, "the MOI group showed some improvement after treatment on the production tasks might have been due to learner output being utilized as input (incidental input) for other learners (p.135). Secondly, those production-oriented tasks which were completed during the treatment may have a positive impact on learners' performance because the production tasks had the same nature in both classroom tasks and assessment tasks. To put it differently, production tasks enabled learners to monitor their answers and provide the answers in the written form in the assessment tasks. Thirdly, the participants in PI group focused on both English future tense and indicative items; while, participants in MOBI group just concentrated on the English future tense. It can be argued that this variance between the PI and MOBI groups provide the suitable ground by which MOBI group can gain better results on the production tasks.

The evidence from this study suggests that MOBI can encourage linguistic development and also establish a direct path to acquisition via the establishment and strengthening of form meaning connections (Morgan-Short \& Bowden, 2006). It can be concluded that instruction type may have a significant effect on L2 learners' performance on the assessment tasks involving the production of English future tense. All in all, the present study suggests that meaningful-output-based instruction can lead to linguistic development and the acquisition of the target form as well as processing instruction group across different tasks. Besides, it indicates that "MOBI seems to have better positive impact on learners' ability to produce" the English future tense (Farley \& Aslan, 2012, p. 136).

The third research question of the present research concerned the difference between PI and MOBI groups in delayed posttests of production and interpretation. The findings of both interpretation and production tasks indicated that participants in the PI group gained better results compared with MOBI group in delayed posttests. It is noteworthy to state that in both interpretation and production tasks, PI outperformed MOBI and had more permanency in acquiring English future tense.

The finding of the third research question supports the findings of previous PI and MOBI studies (e.g. Megharbi, 2007) suggesting that PI group can maintain its gains on both interpretation and production tasks. According to the results, both processing instruction group and meaningful output-based instruction group gained a better result after the treatment on the immediate posttest; however, the improvement of PI group was more salient than MOBI group through the delayed posttest. Therefore, it can be concluded that PI had a positive effect which held over time for all assessment tasks and it can have a positive impact on the learners' interlanguage development.

The findings of the third research question are crucial in contributing to research on processing instruction. Previous studies concluded that PI has a vital role on the acquisition of grammatical structures such as object pronouns in Spanish, the French Causative, the Italian future and the simple present vs. present progressive in English, ser/estar contrast in Spanish.

In general, the findings of the third research question reiterate the positive effects of processing instruction on L2 learners' developing systems. It can be stated that PI helps learners to create form-meaning connections and it plays a vital role in language instruction. In contrast, the MOBI treatment may play some role on the process of language acquisition, but the effect of learning might not be permanent over the period of time.

\subsection{Implications of the Study}

From the pedagogical perspective, the findings of this study may have some implications for SLA 
Vafaparvar, S., \& Shiela, K.

instruction. For one thing, the findings of this study claim that both PI and MOBI can have some functional benefits in classroom language learning and the class curriculum. Teachers can use PI and its input-based activities in the classroom. Moreover, MOBI can help teachers present the English class with some novel activities in which L2 learners can exchange their knowledge and information in both written and oral forms (Farley \& Aslan, 2012). Furthermore, the results of the present study may help teachers to increase L2 learners' attention and awareness in the process of learning. According to Smith (1991), teachers can enhance learners' awareness and noticing by making input more salient. On the other hand, teachers can use feedback during the process of learning. According to the results of this study, feedback in production-based tasks can help learners acquire the target form. As Fukuda (2009) points out, "the production-based activities in the classroom could create a learning environment where learners' mistakes go undetected, which may influence the fossilization of errors in the target grammar points" (p. 156). To sum up, feedback can direct learners' attention to the target form in order to reformulate their knowledge.

\subsection{Limitations of the study}

No study is devoid of limitations, and the current study is no exception. The first limitation deals with the participants. To start with, the participants were selected from pre-intermediate level. Therefore, it is necessary to check whether the findings would be the same for subjects representing other proficiency levels. Moreover, the participants were restricted to female students and the male students were not included in the present study. Besides, the results of the present study are based on the small sample size. In this study, the number of students in each group was small $(n=10)$. The second limitation refers to the grammatical structure. Only one grammatical structure was taught in the present study. Further studies need to be carried out to see whether the interaction among several structures taught together still supports the superiority of PI over MOBI.

\section{References}

Allen, L. Q. (2000). Form-meaning connections and the French causative: An experiment in processing instruction. Studies in Second Language Acquisition, 22, 69-84. https://doi.org/10.1017/S0272263100001030

Benati, A. (2001). A comparative study of the effects of processing instruction and output-based instruction on the acquisition of the Italian future tense. Language Teaching Research, 5, 95-127. https://doi.org/10.1177/136216880100500202

Benati, A. (2005). The effects of processing instruction, traditional instruction, and meaningful based output instruction on the acquisition of English past simple tense. Language Teaching Research, 9, 67-93. https://doi.org/10.1191/1362168805lr154oa

Cadierno, T. (1995). Formal instruction from a processing perspective: An investigation into the Spanish past tense. Modern Language Journal, 19, 179-193. https://doi.org/10.1111/j.15404781.1995.tb05430.x

Cheng, A. C. (2002). The effects of processing instruction on the acquisition of ser and estar. Hispania, 85, 307-325. https://doi.org/10.2307/4141092

Collentine, J. (1998). Processing instruction and the subjunctive. Hispania, 81, 576-587. https://doi.org/10.2307/345673

DeKeyser, R. M., \& Sokalski, K. J. (1996). The differential role of comprehension and production practice. Language Learning, 46(4), 613-642. https://doi.org/10.1111/j.1467-1770.1996.tb01354.x

Erlam, R. (2003). Evaluating the relative effectiveness of structured-input and output-based instruction in foreign language learning. Studies in Second Language Acquisition, 25, 558-583. https://doi.org/10.1017/S027226310300024X

Farley, A. P. (2001a). Processing instruction and meaning-based output instruction: A comparative study. Spanish Applied Linguistics, 5, 56-93.

Farley, A. P. (2001b). Authentic processing instruction and the Spanish subjunctive. Hispania, 84, 289-298. https://doi.org/10.2307/3657760 
The acquisition of the English future tense by Iranian EFL learners

Farley, A., \& Aslan, E. (2012). The relative effects of processing instruction and meaning-based output instruction on L2 acquisition of the English subjunctive. ELT Research Journal, 1(2), 120-141. Retrieved from https://dergipark.ulakbim.gov.tr/eltrj

Fukuda, M. (2009). The effect of processing instruction and meaning-based output instruction on the acquisition of Japanese honorific expressions (Doctoral dissertation, Purdue University). Retrieved from http://docs.lib.purdue.edu/dissertations/AAI3378746/

Izumi, S. (2002). Output, input enhancement, and the noticing hypothesis: An experimental study on ESL relativization. Studies in Second Language Acquisition, 24, 541-577. https://doi.org/10.1017/S0272263102004023

Izumi, S., \& Bigelow, M. (2000). Does output promote noticing and second language acquisition? TESOL Quarterly, 34, 239-278. https://doi.org/10.2307/3587952

Megharbi, N. (2007). The acquisition of the perfective/imperfective aspectual distinction French: Output-based instruction vs. processing instruction (Doctoral dissertation, The University of Texas at Austin). Retrieved from https://repositories.lib.utexas.edu/handle/2152/14640

Morgan-Short, K., \& Bowden, H. W. (2006). Processing instruction and meaningful output-based instruction: effects on second language development. Studies in Second Language Acquisition, 28, 31-65. https://doi.org/10.1017/S0272263106060025

Nagata, N. (1998). Input vs. output practice in educational software for second language acquisition. Language Learning \& Technology, 1, 23-40. Retrieved from https://ltt.msu.edu/vol1num2/article1/default.html

Salaberry, M. R. (1997). The role of input and output practice in second language acquisition. The Canadian Modern Language Review, 53, 422-451. Retrieved from https://www.utpjournals.com/

Smith, M. S. (1991). Speaking to many minds: On the relevance of different types of language information for the L2 learner. Interlanguage Studies Bulletin (Utrecht), 7(2), 118-132. https://doi.org/10.1177/026765839100700204

Swain, M. (1995). Three functions of output in second language learning. In G. Cook \& B. Seidlhofer (Eds.), Principles and practice in applied linguistics: Studies in honor of H. Widdowson (pp. 125-144). Oxford: Oxford University Press.

Swain, M. (2000). The output hypothesis and beyond: mediating acquisition through collaborative dialogue. In J. Lantolf (Ed.), Sociocultural theory and second language learning (pp. 97-114). Oxford: Oxford university press.

Swain, M. (2005). The output hypothesis: theory and research. In E. Hinkel (Eds.), Handbook of research in second language teaching and learning (pp. 471-483). Mahwa, NJ: Lawrence Erlbaum.

Swain, M., \& Lapkin, S. (1995). Problems in output and the cognitive processes they generate: A step towards second language learning. Applied Linguistics, 16, 371-391. https://doi.org/10.1093/applin/16.3.371

Toth, P. D. (2006). Processing instruction and a role for output in second language acquisition. Language Learning, 56(2), 319-385. https://doi.org/10.1111/j.0023-8333.2006.00349.x

VanPatten, B. (1990). Attending to content and form in the input: an experiment consciousness. Studies in Second Language Acquisition, 12, 287-301. https://doi.org/10.1017/S0272263100009177

VanPatten, B. (1996). Input processing and grammar instruction: Theory and research. Westport, CT: Ablex.

VanPatten, B. (2002). Processing instruction: An update. Language Learning, 52, 755-803. https://doi.org/10.1111/1467-9922.00203

VanPatten, B. (2004a). Input processing in SLA. In B. VanPatten (Ed.), Processing instruction: Theory, research, and commentary (pp. 5-31). Mahwah, NJ: Erlbaum.

VanPatten, B., \& Cadierno, T. (1993a). Explicit instruction and input processing. Studies in Second Language Acquisition, 15, 225-243. https://doi.org/10.1017/S0272263100011979

VanPatten, B., \& Cadierno, T. (1993b). Input processing and second language acquisition: A role for instruction. Modern Language Journal, 77, 45-57. https://doi.org/10.1111/j.1540-4781.1993.tb01944.x

VanPatten, B., \& Sanz, C. (1995). From input to output: Processing instruction and communicative tasks. In F. R. Eckman, D. Highland, P. W. Lee, J. Mileham, \& R. R. Weber (Eds.), Second language acquisition theory and pedagogy (pp.169-185). Mahwah, NJ: Lawrence Erlbaum Associates. 
Vafaparvar, S., \& Shiela, K.

VanPatten, B., \& Wong, W. (2004). Processing instruction and the French causative: Another replication. In B. VanPatten (Ed.), Processing instruction: Theory, research, and commentary (pp. 97-118). Mahwah, NJ: Erlbaum. 